\title{
Pulmonary Mucormycosis in an Elderly Patient with multiple Comorbidities
}

\author{
Authors \\ Mukund K. Sasturkar ${ }^{1}$, Sharad B. Biradar ${ }^{2}$ \\ ${ }^{1}$ Head of Internal Medicine Department, Manik Hospital and Research Centre, Aurangabad, Maharashtra, \\ India \\ ${ }^{2}$ Head of Department of Critical Care, Manik Hospital and Research Centre, Aurangabad, Maharashtra, \\ India
}

\begin{abstract}
Pulmonary Mucormycosis, a rare opportunistic invasive pulmonary fungal infection. ${ }^{1}$ Mucormycosis is less common than other opportunistic fungal infections, such as aspergillus and candida infections, but mortality rate is much higher. We report a case of 79 year old male patient with multiple comorbidities who presented to Manik Hospital and Research Centre with 1 month history of cough, fever and breathing difficulty and diagnosed to have pulmonary mucormycosis and treated successfull
\end{abstract}

Keywords: Pulmonary mucormycosis with multiple comorbidities, diagnosis and treatment.

\section{Introduction}

Mucormycosis is an opportunistic fungal infection caused by fungi of order mucorales in the class zygomycetes. Also known as zygomycosis, it is commonly caused by fungal species of genera Rhizopus, Lichtheimia and mucor. ${ }^{2}$ Mucormycosis is manifested by variety of different syndromes, particularly in immunocompramised patients and those with diabetes mellitus. Diabetes remains the most common risk factor; however zygomycosis has increased among transplant recipients and patients with hematological malignancy. ${ }^{3}$ Although most fungal infections, including mucormycosis, are acquired via inhalation, endobronchial manifestation is rare, and the usual presentation is either pulmonary or systemic disease. Diabetes is common predisposing condition for mucormycosis. ${ }^{4}$ Rhino-orbitalcerebral and pulmonary mucormycosis are acquired by inhalation of spores. In healthy individuals, cilia transport these spores to the pharynx and they are cleared through gastrointestinal tract. In susceptible individuals, infection usually begins in nasal turbinates or the alveoli. ${ }^{5}$ The agents of mucormycosis are angioinvasive; thus, infarction of infected tissues is a hallmark of invasive disease. ${ }^{6}$

Amphotericin B is polyene antifungal drug and is the selected drug for the treatment of mucormycosis. $^{7} \quad$ Drug concentration of Amphoctericin B in the lung is lower than other tissues. Therefore pulmonary mucormycosis infection requires a higher dose of A mphoctericin B. Intravenous (IV) amphoctericin B (lipid formulation) is drug of choice for initial therapy. ${ }^{8}$ Liposomal Amphoctericin B is safer, with an improved effect and smaller dose, compared with amphoctericin B alone. ${ }^{9}$ Posaconazole used as a stepdown therapy for those patients who have responded to amphoctericin B. posaconazole is 
broad spectrum azole that is active in against the agents of mucormycosis and that are available in both parenteral and oral formulations. ${ }^{10,11}$

Treatment of mucormycosis involves a combination of surgical debridement of involved tissues and antifungal therapy. ${ }^{12}$ Aggressive surgical debridement of involved tissues should be undertaken as soon as diagnosis of any form of mucormycosis is suspected. There are reports of patients with early pulmonary infection who were cured with lobectomies. ${ }^{13,14}$

Herein we report a case of isolated pulmonary mucormycosis presented as non resolving pneumonia in patient with diabetes mellitus, chronic kidney disease, coronary artery disease (post CABG) who was successfully managed with medical therapy.

\section{Case Report}

A 79 yrs old patient presented in OPD with history of cough with expectoration of purulent yellowish sputum since 1 month, intermittent fever since 3 weeks and breathing difficulty on exertion since 2 weeks. His past history reveals diabetes mellitus and hypertension since $10 \mathrm{yrs}$, ischemic heart disease (post coronary artery bypass surgery 6 yrs ago) and he was diagnosed to have diabetic nephropathy since 2 yrs. He was on regular medications \& follow up for the same. He was nonsmoker and no history of any allergy in past. His X ray chest was done which showed inhomogeneous patchy opacities in right upper \& midzone. CBC revealed leukocytosis. His probable diagnosis was community acquired pneumonia. He was treated with oral antibiotics (cefpodoxime $200 \mathrm{mg} \mathrm{BD}+$ Azithromycin $500 \mathrm{mg}$ OD) for seven days. However patient returned to OPD reporting no relief of cough and fever and increased breathlessness. Hence he was admitted in Hospital.

Clinical Examination on admission revealed

Temp- $37.6^{\circ} \mathrm{C}$

Tachycardia - rate $114 \mathrm{bpm}$

Tachypnea- rate 30/min

BP-140/90 mm of $\mathrm{Hg}$
Spo2- $95 \%$ on room air

RS- chest auscultation revealed decreased breath sounds and scanty Crackels in right supraclavicular and mammary area.

Cardiovascular, central nervous system and abdominal examination was within normal.

Lab investigation on admission:

CBC -

(Hb)-8.9 gm $\%$

(TLC)- 13000

platelet -526000

ESR- 68mm/1

Blood urea- 33.9

Sr creatinine- 1.59

Urine- Alb+

RBSL- 456 mg\%

Na-135 K-4.6

ABG- PH-7.42, PO2- 78 mm hg, PCO2- 44

Sputum exam- Moderate number of gram-positive cocci as well as occasional gram-negative bacilli, AFB : -ve

Gram positive cocci ++

Gram negative bacilli ++

Patient was started with intravenous cephalosporins -

Control of Blood sugar with short acting insulin , and other supportive measures.

However, over next 48 hour, fever not reduced and expectoration and cough persisted. Patient reported minimal increase in dyspnea.

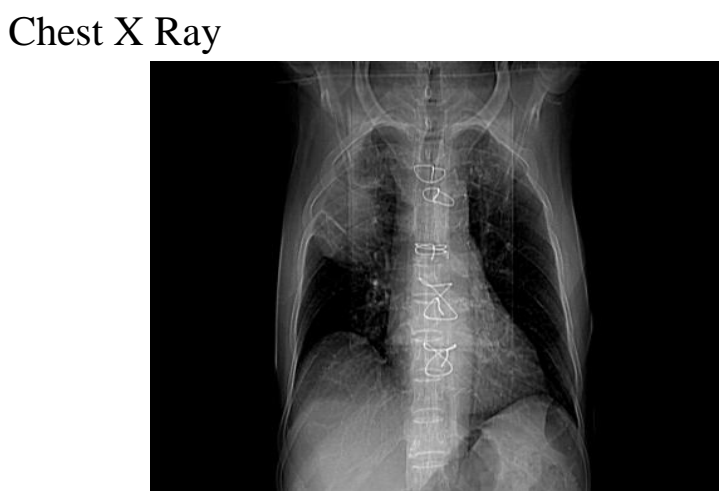

Figure 1 Chest $X$ ray showing right upper lobe haziness 
Blood reports after 2 days

$\mathrm{Hb}-9.2$ gm\%

TLC-30,500

Platelet-4,37,000

Urea-60.9

Creatinine-2.13

Hence we decided to do HRCT chest and Bronchoscopy. HRCT chest showed- large hypodence lesion in right upper lobe with surrounding collapse and foci of air
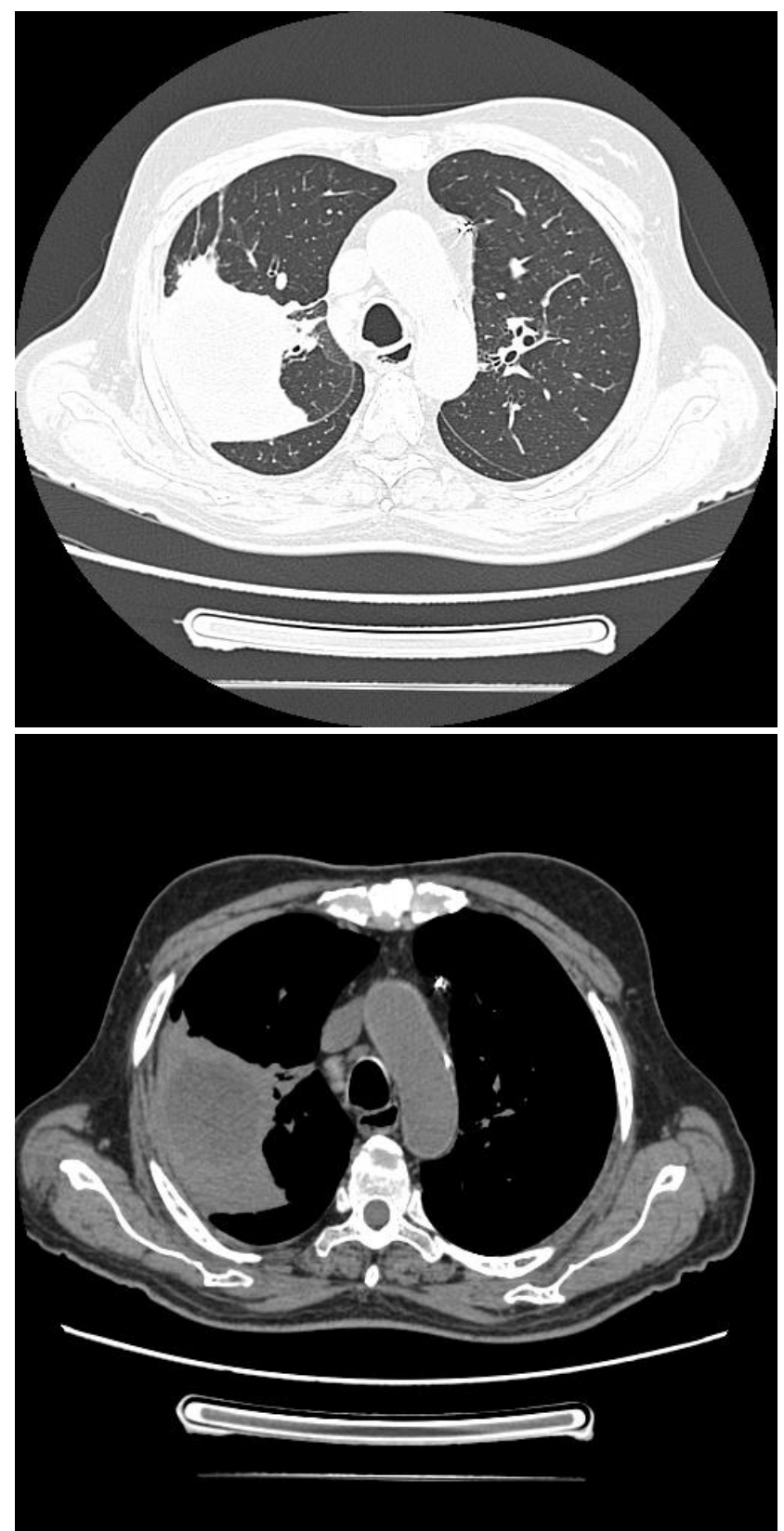

Figure 2. Chest CT showing large hypodence lesion in right upper lobe with surrounding collapse and foci of air within. consolidation in right upper lobe and middle lobe.
Bronchoscopic biopsy showed- both showing fungal hyphae, anthracotic pigment.

Stain- H E 40x $\times 10 x$

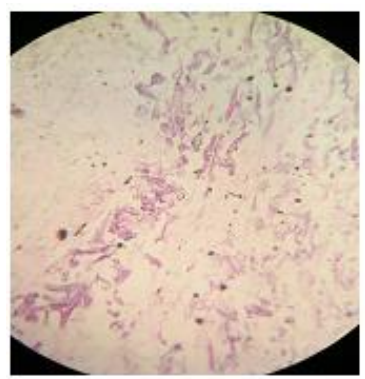

Fig. 3- Bronchoscopy showing fungal hyphae, anthracotic pigment.

His ENT examination and cerebral imaging was normal.

Hence a diagnosis of invasive pulmonary fungal infection-Mucormycosis was established. This was confirmed by the fungal staining \& histopathology report of BAL.

Now we started patient on Inj. Liposomal Amphotericin -B with dose adjustments done according to his renal status. His creatinine clearance was $30.23 \mathrm{ml} / \mathrm{min}$

Over next 14 days he showed gradual clinical improvement. His fever reduced, cough and expectoration reduced. Blood sugars were normal on 3 subcutaneous short acting insulin with meals. His lab after 14 days

$\mathrm{Hb}-9.8 \mathrm{gm} \%$

TLC- 10800

Platelets-515000

Urea- 45.7

Creatinine- 1.78

RBSL- 184

However his chest $\mathrm{X}$ ray \& repeat HRCT revealed same picture after 14 days. At these pt was given option of surgical intervention along with antifungal agents. However he refused for surgery because of multiple comorbidities and age.

Hence we decided to add second line antifungal agent POSICANAZOLE- $\mathrm{mg} / \mathrm{kg} /$ day. i.e. $5 \mathrm{ml}$ BID in syrup form. We continued POSICANAZOLE for one month. During this patient showed good clinical improvement. After 
one month.his HRCT showed complete resolution of lung lesions.

His blood reports at the time of discharge-

$\mathrm{Hb}-9.9 \%$

TLC-9800

Platelet-490000

FBSL-128

PPBS-194

Urea-43.2

Creatinine- 1.56

Thus after one \& half month of antifungal therapy( 1 st +2 nd line antifungal agents) patient showed complete clinical and radiological clearance of pulmonary mucormycosis. $\mathrm{He}$ is on regular follow up till date and asymptomatic.

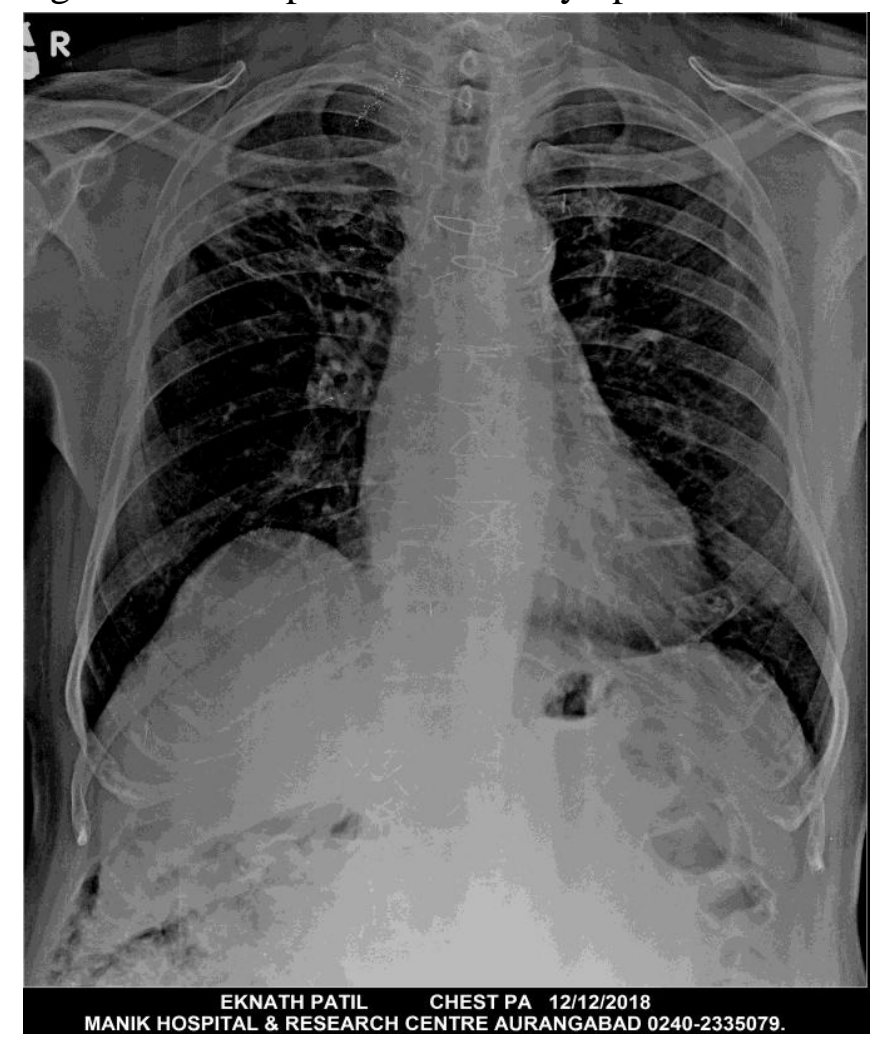

Fig 4. Significant resolution of opacity seen in right upper zone after completion of treatment.

We are reporting this case for following reasons:

1) Incidence of Isolated Pulmonary Mucormycosis is rare.

2) Mortality rate in invasive pulmonary fungal infection is high when associated with comorbidities like diabetes, ischaemic heart disease and Nephropathy. Hence we were successful in complete recovery of patient.
3) Patient had shown only partial clinical response in 14 days of 1 st line drug i.e. inj Liposomal Amphotericin-B. However complete response is achieved when treated with 2nd line antifungal agent. Hence we would like to mention use of 2nd line drugs if 1 st line drugs fail to achieve recovery.

\section{References}

1. Hibbett DS, Binder M, Bischoff JF, Blackwell M, Cannon PF, Eriksson OE, Huhndorf S, James T, Kirk PM, Lucking R, et al. A higher level of phylogenetic classification of fungi. Mycol Res. 2007;111:509-547.

Doi:

10.1016/j.mycres.2007.03.004

2. Petrikkos G, Skiada A, Lortholary O, Roilides E, Walsh TJ, Kontoyiannis DP. Epidemology and clinical manifestation of mucormycosis. Clin infect dis 2012;549 suppl 1):S23-S34

3. Kauffman CA, Malani AN. Zygomycosis: an emerging fungal infection with new options for management. Curr Infect Dis Rep 2007;9:435

4. Epidemiology and outcome of zygomycosis: a review of 929 reported cases. Roden MM, Zaoutis TE, Buchanan WL, Knudsen TA, Sarkisova TA, Schaufele RL, Sein M, Sein T, Chiou CC, ChuJH, Kontoyiannis DP, Walsh TJ. Clin Infect Dis. 2005;41(5):634

5. Mucormycosis of nose and paranasal sinuses. Ferguson BJ. Otolaryngol Clin North Am. 2000;33(2):349.

6. Zygomycosis (mucormycosis): emerging clinical importance and new treatments. Greenberg RN, Scott LJ, Vaughn HH, Ribes JA. Curr Opin Infect Dis. 2004;17(6):517

7. Li WF, He C, Liu XF,Wang SY,QuJL, Lin ZF. A diagnosis neglected for 6 years; Report of a misdiagnosed case of pulmonary mucormycosis and review of 
literature. Chin Med J (Engl) 2010;123: 2480-2482.

8. Mold infections of central nervous system. McCarthy M, Rosengart A, S chuetz AN, Kontoyiannis DP, Walsh TJ. N Engl J Med. 2014 Jul;371(2):150-60.

9. Wolf O, Gil Z, Leider-Trejo L, Khafif A, Biderman P, Fliss DM. Tracheal mucormycosis presented as intraluminal soft tissue mass. Head Neck. 2004;541543.

10. New agents in treatment of fungal infections: clinical efficacy and gaps in coverage. Spanakis EK, Aperis G, Mylonakis E. Clin Infect Dis. 2006;43(8):1060. Epub 2006 Sep 8.

11. In vitro activities of posaconazole, itraconazole, voriconazole, amphoctericin $\mathrm{B}$, and fluconazole against 37 clinical isolates of zygomycetes. Sun QN, Fothergill AW, McCarthy DI, Rinaldi MG, Graybil JR. Antimicrob Agents Chemother. 2002;46(5):1581.

12. Mucormycoses. Farmakiotis D, Kontoyiannis DP. Infect Dis Clin North Am. 2016 Mar;30(1):143-63.

13. Pulmonary mucormycosis: results of medical and surgical therapy. Tedder M, Spratt JA, Anstadl MP, Hegde SS, Tedder SD, Lowe JE. Ann Thorac Surg. 1994;57(4):1044.

14. Broncovascular mucormycosis in the diabetic: an urgent surgical problem. Brown RB, Johnson JH, Kessinger JM, Sealy WC. Ann Thorac Surg. 1992;53(5):854. 